$\mathrm{P}=0,018)$, что обеспечило значительную динамику показателя $\mathrm{XC}$-не ЛВП $(-27 \%$, $\mathrm{P}=0,0032)$ и АИ $(-30 \%, \mathrm{P}=0,0124)$. Снижение уровня ТГ составило $-6,6 \%$, но не достигло уровня статистической значимости.

Анализ результатов к 48-ой неделе гиполипидемической коррекции сочетанной ГЛП у пациентов с ИБС с использованием подхода двойного ингибирования ОХС показал, что гипохолестеринемический эффект реализовался за счет снижения уровня $\mathrm{XC} \mathrm{ЛНП} \mathrm{(-21,5 \% ,} \mathrm{P=0,001),} \mathrm{OXС} \mathrm{(-14,5 \% ,} \mathrm{P=0,02),} \mathrm{ТГ}(-11,2 \%, \mathrm{P}=0,03)$. Двойное ингибирование синтеза ХC оказало влияние на обратный транспорт ХC, что проявилось повышением показателя ХС ЛВН на 4,5\% (уровень статистической значимости не достигнут).

На основе полученных результатов, можно сделать вывод о том, что добавление эзетимиба в дозе 10мг в сутки к терапии ингибиторами синтеза ОХС, позволяет увеличить процент пациентов достигших целевых уровней по показателю ХС ЛНП на $30 \%$ у пациентов резистентных к ранее проводимой монокомпонентной гиполипидемической терапии, что расширяет возможности как вторичной, так и первичной профилактики у пациентов, страдающих ИБС с атерогенными ГЛП.

$$
* * *
$$

1. Дзвониская, В.Н. Влияние индивидуальных особенностей окислительного метаболизма и генетических факторов на эффект гиполипидемической терапии у больных ишемической болезнью сердца: автореф. дис. канд. мед. наук: 14.03.06 / В.Н. Дзвониская. - Курск, 2011. - 22 с.

2. Carotid intima-media thickness in low-risk individuals with asymptomatic atherosclerosis: baseline data from the METEOR study / J.R. Crouse 3rd [et al.] // Curr. Med. Res. Opin. - 2007. - Vol. 23, N 3. - P. 641-648.

3. Changes in plaque lipid content after short-term intensive versus standard statin therapy: the YELLOW trial (reduction in yellow plaque by aggressive lipid-lowering therapy) / A.S. Kini [et al.] //J. Am. Coll. Cardiol. - 2013. - Vol. 62, N 1. - P. 21-29.

\title{
Оганесян Д.X. \\ Влияние экспериментальной гиперкальциемии на показатели системной гемодинамики в условиях интоксикации хлоридом кобальта и цинка
}

«Северо-Осетинская государственная медицинская академия» Министерства здравоохранения Российской Федераџии

(Россия, Владикавказ)

doi:10.18411/spc-15-10-2017-06

idsp: 000001:spc-15-10-2017-06

\section{Аннотация}

Работа заключается в изучении особенностей изменения параметров системной гемодинамики под влиянием хлорида кобальта и цинка в условиях гиперкальциемии. Экспериментальную гиперкальциемию у крыс линии Вистар создавали путём ежедневного интрагастрального однократного введения 10\% раствора хлорида кальция в количестве 0,3 мл на 100 г массы крысы в течение 30 дней. Хлорид кобальта вводили внутрижелудочно с помощью зонда, в дозе 4 мг/кг ежедневно на протяжении одного месяца. Аналогичным способом вводили хлорид цинка в дозировке 20 мг/кг. По истечении времени эксперимента исследовали функциональное состояние сердечной сосудистой системы, определяя основные параметры системной гемодинамики. Изучались следующие показатели: артериальное давление - инвазивно (кровавым способом) путём введения в бедренную артерию пластикового катетера. Для измерения минутного объёма крови через левую общую сонную артерию в дугу аорты вводился термистор. Показания регистрировались с помощью монитора MX-04. Рассчитывалось среднее артериальное давление по специальной формуле, частота сердечных сокращений - с помощью хирургического монитора; по специальным формулам 
рассчитывались сердечный индекс, ударный индекс и удельное периферическое сосудистое сопротивление. Исследования показали, что внутрижелудочное введение хлорида кобальта и цинка вызывает изменения параметров системной гемодинамики, которые проявляются в виде артериальной гипертензии. При экспериментальной гиперкальциемии, вызванной введением хлорида кальция, введение цинка вызывает достоверно меньшую гипертензивную реакцию.

Ключевые слова: тяжёлые металлы, хлорид кобальта, хлорид цинкагемодинамика, гиперкальциемия.

\section{Abstract}

The work consists in studying the features of the change in the parameters of systemic hemodynamics under the influence of cobalt and zinc chloride under conditions of hypercalcaemia. Experimental hypercalcaemia in Wistar rats was created by daily single administration of a $10 \%$ solution of calcium chloride in an amount of $0.3 \mathrm{ml}$ per $100 \mathrm{~g}$ of rat weight for 30 days. Cobalt chloride was injectedintragastrically with a probe, at a dose of 4 $\mathrm{mg} / \mathrm{kg}$ daily for one month. Zinc chloride was administered in a similar manner at a dosage of $20 \mathrm{mg} / \mathrm{kg}$. After the expiration of the experiment, the functional state of the cardiac vascular system was examined, determining the main parameters of systemic hemodynamics. The following indicators were determined: blood pressure - invasively (bloody way) by inserting a plastic catheter into the femoral artery. To measure the minute volume of blood through the left common carotid artery in the aortic arch, a thermistor was inserted. The readings were recorded using the MS-04 monitor. Mean arterial blood pressure was calculated according to a special formula, heart rate - using a surgical monitor; according to special formulas, the cardiac index, the shock index and the specific peripheral vascular resistance were calculated. Studies have shown that intragastric administration of cobalt and zinc chloride causes changes in the parameters of systemic hemodynamics, which manifest themselves in the form of arterial hypertension. With experimental hypercalcaemia caused by the introduction of calcium chloride, the introduction of zinc causes a significantly lower hypertensive reaction

Key words: heavy metals, cobalt chloride, zinc chloride hemodynamics, hypercalcemia.

\section{Введение}

Кальций - один из наиболее важных макроэлементов в организме. У здорового человека в организме содержится 1,5 -2 кг кальция, большая часть которого преимущественно локализуется в костной ткани. Участвуя во многих биологических процессах, он обеспечивает сокращение миокарда[6], скелетных и гладких мышц, является важнейшим фактором гемостаза, регулирует активность нервной системы. Ионы кальция служат посредниками во внутриклеточной передаче сигналов, участвуют в обеспечении системы активного внутриклеточного транспорта, в синаптической передаче и других жизненно важных функциях[2]. Многочисленность выполняемых функций объясняет и наличие жёстких механизмов регуляции концентрации кальция в крови. Поддержание постоянства концентрации кальция в организме регулируется его реабсорбцией в канальцевом аппарате почек, всасыванием в кишечнике и метаболизмом в костной ткани[2] [4].

Цинк -является одним из распространённых ксенобиотиков, который относится к веществам второго класса опасности. Выявлено, что антропогенное поступление цинка в окружающую среду превышает природное более чем в 4 раз. Являясь кофактором большой группы ферментов, участвующих во всех видах обмена, он необходим для нормального течения многих биохимических процессов[5]. Цинк принимает активное участие в процессе стабилизации мембраны клеток и является 
мощным составляющим антиоксидантной системы. Кроме того, металл является компонентом ферментных активаторов секреции и реабсорбции веществ в почках[8].

Повышенное поступление цинка в организм животных сопровождается снижением содержания кальция в крови, и в костях[7], предполагается это связано с тем что, цинк вытесняет кальций из транспортных систем, замещая его, вместе с этим нарушается усвоение фосфора, в результате развивается остеопороз. Ряд зарубежных авторов экспериментальным путём на животных показали роль дефицита цинка в развитии сердечно-сосудистой патологии[9], однако данных о воздействии избытка цинка на параметры системной гемодинамики, и взаимосвязь этих эффектов от состояния обмена кальция явно недостаточно.

Кобальт относится к жизненно важным микроэлементам, он необходим для работы различных систем организма, но при этом, избыточные концентрации металла для организма токсичны и даже губительны.

Повышенное поступление кобальта в организм оказывает патогенное действие на сердечную ткань, в частности способствует развитию инфаркта миокарда[10] и повышению артериального давления[4], о чем свидетельствует ряд научных работ.

Одним из известных механизмов токсического влияния тяжёлых металлов на организм является их свойство замещать кальций в специфических биохимических процессах. Экспериментальным методом было выявлено, что высокая концентрация кальция в рационе препятствует проникновению и кумуляции свинца в органах и тканях, способствует выведению его из организма вместе с мочой, в значительной степени снижая его токсическое действие, что говорит о протекторной активности кальция в условиях интоксикации свинцом[1]. Что же касается публикаций о протекторном влиянии кальция на развитие кобальтовой или цинковой интоксикации в доступной литературе мы их не обнаружили.

\section{Объекты и методы исследования}

Работа была выполнена на 75 половозрелых крысах-самцах линии Вистар со

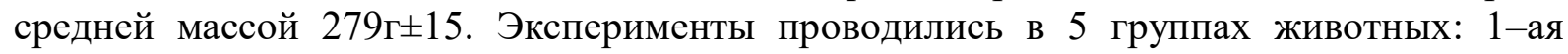
группа - контрольные крысы, 2-ая группа - животные с внутрижелудочным (в|ж) введением хлорида цинка в дозе 20 мг Кк (суточная доза), 3-я группа - животные с интрагастральным введением хлорида цинка в дозе 20 мг Ккг и с экспериментальной гиперкальциемией, вызванной введением кальция хлорида. 4-ая группа - животные с внутрижелудочным (в\ж) введением хлорида кобальта в дозировке 4 мгџкг (суточная доза), 5-я группа - животные с интрагастральным введением хлорида кобальта в дозе 4 мг\кг и с экспериментальной моделью гиперкальциемии, вызванной введением кальция хлорида в количестве 0,3 мл на 100 г массы. Животные находились на стандартном пищевом рационе, имели свободный доступ к воде и пище. Световой режим естественный. Модель гиперкальциемии создавалась путём ежедневного интрагастрального однократного введения 10\% раствора хлорида кальция в количестве 0,3 мл на 100 г массы крысы в течение 30 дней. В опыт отбирались крысы с отчётливой гиперкальциемией $(3,93 / 4,70$ ммоль/л) (в контроле 2,30/2,78) - (содержание кальция в крови/в плазме). Концентрацию кальция определяли на анализаторе электролитов АЭК-01. По окончанию эксперимента (30 дней) исследовали функциональное состояние сердечной-сосудистой системы, определяя основные параметры системной гемодинамики. Определение показателей гемодинамики проводилось в остром эксперименте под нембуталовым наркозом. Определялись показатели: артериальное давление - прямым способом путём катетеризации бедренной артерии. Показания артериального давления фиксировались с помощью монитора MX-04. Рассчитывалось среднее артериальное давление (САД) по формуле САД =ДД $+1 / 3$ ПД, где ДД диастолическое давление, ПД - пульсовое давление; частота сердечных сокращений (ЧСС) определялась - с помощью монитора MX-04; Для регистрации сердечного выброса крови через левую сонную артерию в дугу аорты вводился термистор МТ- 
54M. Через яремную вену вводился катетер в правое предсердие, через него иньецировали физиологический раствор фиксируемой температуры в количестве 0,2 мл. Кривые терморазведения регистрировали на самописце. По формулам рассчитывались сердечный индекс (СИ), ударный индекс (УИ) и удельное периферическое сосудистое сопротивление (УПСС). Статистическая обработка результатов, учитывая количество выборок и нормальное распределение рядов сравнения, найденное с помощью критерия Шапиро-Уилка (Wф>>Wm), проводилась с применением критерия «t» Стьюдента (U-критерий Манна - Уитни) с использованием программы GraphPad Prizm 6.

\section{Результаты и их обсуждение.}

Измерение показателей системной гемодинамики выявило, что у крыс с внутрижелудочным введением хлорида цинка происходит достоверное увеличение среднего артериального давления (САД) по сравнению с фоновой группой животных, что было обусловлено значимым увеличением удельного периферического сосудистого сопротивления (таблица).

Таблиияа

Влияние гиперкальциемии на показатели системной гемодинамики в условиях кобальтовой и цинковой интоксикации

\begin{tabular}{|c|c|c|c|c|c|c|}
\hline $\begin{array}{c}\text { Условия } \\
\text { опыта }\end{array}$ & $\begin{array}{c}\text { Стат. } \\
\text { показа } \\
\text { тель }\end{array}$ & $\begin{array}{c}\text { Среднее } \\
\text { артериальное } \\
\text { давление (мм } \\
\text { рт.ст) }\end{array}$ & $\begin{array}{c}\text { Частота } \\
\text { сердечных } \\
\text { сокращений } \\
\text { (уд.в мин.) }\end{array}$ & $\begin{array}{c}\text { Сердечны } \\
\text { й индекс } \\
\text { (мл/100г) }\end{array}$ & $\begin{array}{c}\text { Ударный } \\
\text { индекс(мл/10 } \\
\text { 0г) }\end{array}$ & \begin{tabular}{|c|} 
Удельное \\
периферическое \\
сосудистое \\
сопротивление(усл. \\
ед) \\
\end{tabular} \\
\hline $\begin{array}{c}\text { 1-я } \\
\text { группа } \\
\text { Фон }\end{array}$ & $\mathrm{M} \pm \mathrm{m}$ & $103.3 \pm 0,81$ & $380 \pm 5,20$ & $54,24 \pm 1,35$ & $0,141 \pm 0,003$ & $1,55 \pm 0,044$ \\
\hline \multirow{2}{*}{$\begin{array}{c}\text { 2-я } \\
\text { группа } \\
\mathrm{Zn} \mathrm{B/Ж}\end{array}$} & $\mathrm{M} \pm \mathrm{m}$ & $123.3 \pm 2.21$ & $385.5 \pm 8.79$ & $41.89 \pm 1.29$ & $0.108 \pm 0.001$ & $2.37 \pm 0.071$ \\
\hline & $\mathrm{p}$ & $* ! !)$ & $* ! !)$ & $*$ & $* ! !)$ & $*$ \\
\hline \multirow{2}{*}{$\begin{array}{c}\text { 3-я } \\
\text { группа } \\
\mathrm{Zn} \mathrm{B} / Ж \\
+\mathrm{CaCl}\end{array}$} & $\mathrm{M} \pm \mathrm{m}$ & $115.6 \pm 3.40$ & $353 \pm 6.126$ & $42.29 \pm 0.09$ & $0.119 \pm 0.002$ & $2.187 \pm 0.071$ \\
\hline & $\mathrm{p}$ & *\# & *\#!!) & *\#!!) & *\#!!) & *\# \\
\hline \multirow{2}{*}{$\begin{array}{c}\text { 4-я } \\
\text { группа } \\
\text { Co B/Ж }\end{array}$} & $\mathrm{M} \pm \mathrm{m}$ & $135.1 \pm 3,6$ & $400 \pm 8,2$ & $42,09 \pm 2,6$ & $0,105 \pm 0,005$ & $2,66 \pm 0,223$ \\
\hline & $\mathrm{p}$ & *\# & *\# & * & *\# & $* ! !)$ \\
\hline \multirow{2}{*}{$\begin{array}{c}5-я \\
\text { группа } \\
\mathrm{Co} \\
\mathrm{B} / Ж+\mathrm{Ca} \\
\mathrm{Cl} \\
\end{array}$} & $\mathrm{M} \pm \mathrm{m}$ & $132.1 \pm 2.73$ & $418 \pm 14.3$ & $47.13 \pm 1.4$ & $0.113 \pm 0.005$ & $2.26 \pm 0.101$ \\
\hline & $\mathrm{p}$ & \#!!) & \# & \# & \# & \# \\
\hline \multicolumn{7}{|c|}{$\begin{array}{c}\text { Примечание: }(*) \text { - достоверное }(\mathrm{p}<0,001) \text { изменение по сравнению с фоном; } \\
(* *) \text { - достоверное }(\mathrm{p}<0,05) \text { изменение по сравнению фоном; } \\
(\#) \text { - достоверное }(\mathrm{p}<0,001) \text { изменение по сравнению с группой№1; } \\
(\# \#) \text { - достоверное }(\mathrm{p}<0,05) \text { изменение по сравнению группой№2; } \\
(! !) \text { - достоверное }(\mathrm{p}<0,05) \text { изменение по сравнению группой№3; } \\
\text { М-среднее арифметическое значение выборки } \\
\text { m-ошибка средней арифметической }\end{array}$} \\
\hline
\end{tabular}

При интрагастральном введении металла происходило изменение насосной функции сердца, что проявляется снижением сердечного индекса, вследствие уменьшения ударного индекса относительно значений интактного контроля. Увеличение частоты сердечных сокращений у экспериментальных животных, 
получавших хлорид цинка относительно фоновых значений, носит компенсаторный характер, связанный с повреждающим свойством тяжёлого металла и особенностью его замещать кальций в некоторых биохимических реакциях. Аналогичная картина наблюдалась и в группе животных изолированно получавших хлорид кобальта, однако эффекты были более выражены по сравнению с контрольной группой и серией крыс, получавших хлорид цинка.

Несколько иная картина наблюдалась в группе животных с экспериментальной моделью гиперкальциемии при введении хлорида цинка. Повышенная концентрация кальция в крови в условиях внутрижелудочного введения цинка приводит к меньшему подъёму среднего артериального давления по сравнению с группой животных, изолированно получавших хлорид цинка, что было обусловлено наличием менее выраженных изменений удельного периферического сосудистого сопротивления. Одновременно с этим была замечена тенденция к восстановлению сердечного и ударного индексов относительно значений группы животных с изолированным введением металла, что позволяет говорить об улучшении насосной функции сердца в условиях гиперкальциемии. Что касаемо серии опытов с введением хлорида кобальта в условиях длительного введением хлорида кальция, установлено, что изменения были менее достоверно выражены.

\section{Заключение}

Исходя из вышеизложенного, можно сделать вывод о том, что тяжёлые металлы, (цинк, кобальт) вызывают изменения параметров системной гемодинамики, которые проявляются в виде артериальной гипертензии гипокинетического типа. При сочетанном введении хлорида кальция и хлорида цинка наблюдается достоверное уменьшение выраженности сдвигов показателей гемодинамик, что не было выявлено при введении кобальта и хлорида кальция. Таким образом гиперкальциемия оказывает протекторный эффект лишь на гипертензивное действие цинка.

$$
* * *
$$

1. Ахполова В. О., Брин В. Б. Сравнительная характеристика влияния внутрижелудочного и подкожного введения ацетата свинца на функции почек в условиях экспериментального гипервитаминоза Д // Вестник новых медицинских технологий. - 2009. - Т.16. №04 - с. 164-165

2. Брин В.Б. // Избранные лекции по современной физиологии под ред. акад. РАН М.А. Островского, чл.-корр. РАМН А.Л. Зефирова. Казань, -2010 г. -С.216-242

3. Патент 2462762 Российская Федерация МПК G09B 23/28(2006.01).Способ моделирования хронической токсической артериальной гипертонии и кардиопатии у экспериментальных животных // Брин В.Б., Митциев А. К., Кабисов О. Т., Митциев К. Г. № 2011128446/14; заявл. 08.07.2011; опубл. 27.09.2012Бюл. № 27

4. Бузоева М.Р., Брин В.Б. // Вестник новых медицинских технологий. -2009. -Т. XVI. - № 3. -C. 170 171.

5. Гичев Ю.П. Загрязнение окружающей среды и здоровье человека (Печальный опыт России).Новосибирск. Изд-во СО РАМН, 2002. - 230с.

6. Иорданская Ф. А., Цепкова Н. К. Кальций в крови: диагностическое и прогностическое значение в мониторинге функционального состояния высококвалифицированных спортсменов // Вестник спортивной науки.

7. Влияние колебаний содержания металлов в крови на их содержание в тканях лабораторных животных при нормальном и избыточном пищевом потреблении // Ревякин А.О., Каркищенко Н.Н., Шустова. Е.Б., Каркищенко В.Н., Ксенофонтова Д.А../ Биомедицина. - 2013. -№4.-С. 16.

8. Цаллаева Р.Т., Брин В.Б. Влияние внутрижелудочного и подкожного введения хлорида цинка на электролито-водовыделительную функцию почек при экспериментальной гипокальциемии. // Современные проблемы науки и образования. - 2014. №2 - С.1-7.

9. A Serum calcium, magnesium, copper and zinc and risk of cardiovascular death / A.Reunanen, P. Knekt, J. Marniemi. etal. // Eur. J. Clin. Nutr.- 1996.- № 50 (7).-P. 431-438.

10. Linna, Exposure to cobalt in the production of cobalt and cobalt compounds and its effect on the heart / A. Linna, P. Oksa, K. Groundstroem, M. Halkosaari, P. Palmroos // Occupational and Environmental Medicine. — 2004.— Vol. 61. — № 11. - P. 877-885 